\title{
Historical technological impacts on the visual representation of language with reference to South Asian typeforms
}

Article

Accepted Version

Ross, F. ORCID: https://orcid.org/0000-0002-1094-2961 (2018) Historical technological impacts on the visual representation of language with reference to South Asian typeforms. Philological Encounters, 3 (4). ISSN 2451-9189 doi: https://doi.org/10.1163/24519197-12340054 Available at https://centaur.reading.ac.uk/66725/

It is advisable to refer to the publisher's version if you intend to cite from the work. See Guidance on citing.

To link to this article DOI: http://dx.doi.org/10.1163/24519197-12340054

Publisher: Brill

All outputs in CentAUR are protected by Intellectual Property Rights law, including copyright law. Copyright and IPR is retained by the creators or other copyright holders. Terms and conditions for use of this material are defined in the End User Agreement.

www.reading.ac.uk/centaur 
Central Archive at the University of Reading

Reading's research outputs online 
Fiona Ross

\section{Historical technological impacts on the visual representation of language with reference to South-Asian typeforms.}

The scripts of South Asia, which mainly derive from the Brahmi script, afford a visible voice to the numerous linguistic communities that form over one fifth of the world's population. However, the transition of these visually diverse scripts from chirographic to typographic form has been determined by historical processes that were rarely conducive to accurately rendering non-Latin scripts.

This essay provides a critical evaluation of the historical technological impacts on typographic textual composition in South-Asian languages. It draws on resources from relevant archival collections to consider within a historical context the technological constraints that have been crucial in determining the textural appearance of South-Asian typography. In so doing, it seeks to elucidate design decisions that either purposely or unwittingly shaped subsequent and current typographic practice and questions the validity of the continued legacy of historical technological impacts for contemporary vernacular communication.

Key words:

South Asia

Typography

Typefounding

Typesetting

Devanagari

Bengali

\section{The historical technological impacts on the visual representation of language with reference to South Asian typeforms.}

The typographic rendition and reproduction of the world's many writing systems have indubitably facilitated the dissemination of information, sharing of knowledge and stimulation of cultural interchange. However, the development of typeforms for the numerous scripts of South Asia that represent seemingly innumerous languages has been greatly influenced by the prevailing typefounding and typesetting technologies initially conceived for the Latin script; these influences are still visible in current typographic practice. Archival research provides an understanding of the historical technological impacts on typographic textual composition in South-Asian languages; furthermore, it raises questions concerning the validity of the continued legacy of these historical approaches for contemporary vernacular communication.

Curiously perhaps, printing in non-Latin scripts predates that in Latin not only by means of xylography, whose use within and from China proliferated and spread from at least 700 $\mathrm{CE}$, but also by movable type in East Asia and even metal type known to have been 
successfully produced in Korea in the thirteenth century. ${ }^{1}$ Yet many languages and their associated scripts saw representation in type some centuries after Latin-script incunabula. Some even have yet to be realized. The relative lateness of the typographic representation of the diverse voices of South Asia has often been attributed to the prevalence and veneration of oral transmission. ${ }^{2}$ Indeed, orality is known to have long remained a powerful influence in some societies with written literature being orally performed. Moreover, even with the 'epistemic revolution of literacy' the people of South Asia exhibited a preference for scribal practices over print in relation to their literary cultures. ${ }^{3}$

Nonetheless, manuscript scriptoria were eventually displaced in South Asia by the introduction of European typefounding and print technologies; and it can be said that current Indian-script typeforms still owe much to the forms initiated in metal, usually by foreign hands and methods, that began with the casting of Tamil types towards the end of the sixteenth century. ${ }^{4}$ Irrespective of the script, throughout type history a range of motivating forces has impelled the conception of founts and the development of new typefaces. ${ }^{5}$ These forces, be they evangelical, political, educational, or even aesthetic, were concomitant with the knowledge and skills of the actual craftsmen, and contributed implicitly to the outcomes to the shaping of the resulting printed images. Yet it is the prevailing type-making technology, usually entwined with economic considerations, that has commonly been seen as the key determinant in how languages are rendered visible in print. Furthermore, particular typographic conventions of representing languages became 'fixed' at different periods in Indian type history - whether in metal foundry type, hot-metal machine composition, or cold type - and these conventions have been perpetuated throughout the centuries even by the growing number of autochthonous foundries. ${ }^{6}$ They have persisted despite the emergence of radically different type-making technologies that, in the digital era, culminated in the dematerialization of type.

\section{Initial steps}

Latin typography, as understood by the Europeans in India or by professional British type

\footnotetext{
${ }^{1}$ Graham Shaw, "Non-Latin scripts and printing technologies," in Non-Latin scripts: From hot-metal to digital type, eds Fiona Ross and Vaibhav Singh, (London: St Bride Library, 2012), 21.

${ }^{2}$ Florian Coulmas, The Writing Systems of the World (Basil Blackwell, Oxford, 1991), 179.

${ }^{3}$ Sheldon Pollock, "Literary Culture and Manuscript Culture in Precolonial India," in Literary Cultures and the Material Book, ed. Simon Elliot et al. (London: The British Library, 2007), 77-81.

${ }^{4}$ [G. Shaw] "Indian Manuscripts, An introduction to the permanent exhibition," British Library information sheet, 1977.

${ }^{5}$ See F. Ross, The Printed Bengali Character and its Evolution, (Richmond: Curzon Press, 1999), 116-117. A 'fount' is a metal rendering of typeface in a particular size. Most definitions of terms used within this essay are the author's own or sourced from Linotype \& Machinery, A Dictionary of Printing Terms (London, 1962). For a more extensive glossary, see Ross, Printed Bengali Character, 236-237.
}

${ }^{6} \mathrm{~A}$ 'foundry' is an establishment where the types are cast. 
founders at home, was hardly an appropriate model to follow for fashioning Brahmi-derived scripts in metal for the production of prefabricated letterforms, albeit initially for translations of Christian texts. The first known book to have been printed in an Indian script was a small catechism in Tamil printed in $1577,{ }^{7}$ although it was not until the mid nineteenth century that the typographic development of Tamil and other South Asian scripts can be said to have begun in earnest. For Tamil, comprehending the writing system and then cutting and casting the full range of required characters would not perhaps have seemed unduly daunting: as in all Indian scripts Tamil is unicase ${ }^{8}$ and, like other scripts of South India, it is non-joining; yet unlike many it does not have a particularly extensive character repertoire. ${ }^{9}$

A complete understanding of the writing system remains a prerequisite for the successful typographic rendition of any language, and is essential to establishing the character repertoire, i.e. the number of sorts, ${ }^{10}$ that is also controlled by the method of composition and vice versa. Attempts at replicating the Devanagari script in type attributed to the experienced London type founder Joseph Jackson in the 1780s afford a salutary illustration of the importance of knowledge of the script and scribal practice. The specimens of the typeface, a sheet of which is bound into a copy of William Kirkpatrick's A Vocabulary, Persian, Arabic and English (Calcutta, 1785) [fig. 1] indicate both that Jackson had a model to follow (the detail of the types testify to this) and that he failed to understand, at least initially, the consequences of the proposed design in practical typefounding and composition terms. In this specimen, Devanagari consonants are shown with vowel signs that vary in angle and length according to the base character, as obtains naturally in handwriting. This indicates that he followed the presumably hand-written model too faithfully rather than rationalized the forms by creating one set of vowel signs for use with all consonants. Consequently, the complete fount would have necessitated an inordinate number of ligatures to properly represent the script. ${ }^{11}$

The Indian writing system is classed as an alpha-syllabary ${ }^{12}$ which utilizes vowel signs to alter the inherent ' $a$ ' syllable of each consonant, and can have an indeterminate number of

\footnotetext{
${ }^{7}$ G. Shaw, "A revised outline of early South Asian printing," South Asia Library Group Newsletter 34 (1989), 19.

8 'Unicase' does not have upper-case [capital] letters.

${ }^{9}$ Coulmas, Writing Systems, 192-3. The inherent difficulty of wide, intricate Tamil typeforms was an issue that would be encountered later in mechanical typesetting, see below.

${ }^{10} \mathrm{~A}$ 'sort' is an individual piece of type, whether a single character or a combination of characters and/or diacritical marks.

${ }^{11}$ A 'ligature' in this essay pertains to combinations of consonants and vowels in Indian scripts whereby another shape is produced, and so would require separate 'sort'.

${ }^{12}$ C. Shackle, P.O. Skjaervo, "South and SouthEast Asia: Scripts," in Encyclopedia of Languages and Linguistics, $2^{\text {nd }}$ edn (Elsevier, 2006), 546.
} 
consonantal clusters ${ }^{13}$ depending on the language represented and the use of loan words or neologisms. In Devanagari these consonantal clusters, known as conjuncts, alter in shape according to various principles or conventions and can number in the hundreds [fig.2]. Therefore, the concept of including ligatures comprising different variations of vowel signs with each consonant, and by extension with each conjunct, would necessitate a fount of many thousands of sorts. ${ }^{14}$ Jackson would have appreciated the costs of materials and the additional labour of casting and typesetting from an extraordinarily large character set. Furthermore, the variations in vowel-sign angle and length, as well as uneven stroke weights, make for an imbalanced design, as can be seen from its rare use in Kirkpatrick's Vocabulary (Calcutta, 1799). Nonetheless, Jackson's fount is said to have inspired the design of the types used for the publication of The New Asiatick Miscellany by the Chronicle Press (Calcutta, 1789), reputedly the earliest known use of Devanagari moveable types in India. ${ }^{15}$ Jackson's earlier attempt at Bengali typefounding, however, had met with even less success. ${ }^{16}$

The first successful fount of Bengali types was cut and cast in India, allegedly singlehandedly, by Charles Wilkins. ${ }^{17}$ This predates Jackson's foray into Devanagari typefounding and demonstrates a different approach to composing Indian scripts. Commissioned in lieu of Jackson's Bengali types for Nathaniel Brassey Halhed's A Grammar of the Bengal Language (Hoogly, 1778), ${ }^{18}$ the fount shows the rationalized use of vowel signs, with a few alternative designs for special contextual use, rather than attempts to replicate the variations of manuscript forms. For the creation of some conjuncts the Grammar employs common components added to the base character in the way taught to those learning the script, as described by Halhed:

a set of distinct characters were invented, called ... P'holaa' or adjuncts. They are certain subordinate and subsidiary figures, that may be attached to each of the consonants in the alphabet respectively, to provide against the too frequent recurrence of the internal vowel. ${ }^{19}$

\footnotetext{
13 'Conjuncts' or 'consonantal clusters' are combinations of consonants with no intervening vowels.

${ }^{14}$ See B.S. Naik, Part Four, "Frequency Studies of Devanagari Graphemes and Type Sorts", specifically pages 425-426 in Typography of Devanagari, Vol.2, (Bombay, 1971).

${ }^{15}$ G. Shaw, "Printing in Devanagari - Monotype's important role in the growth of printing in India," The

Monotype Recorder, (New Series, Number 2, September, Redhill, 1980), 29-30. Jackson's method of composition was probably modelled on the first Devanagari moveable types cast in Rome and designed by Indian converts used in Alphabetum Brammhanicum (Rome, 1771).

${ }^{16}$ Commissioned by William Bolts, who had seemingly supplied Jackson with unsatisfactory letterform models; Talbot Baines Reed, A History of Old English Letter Foundries, (London, 1887), 318-9. The fount was probably never completed; Ross Printed Bengali Character, 80.

${ }^{17}$ See Ross, Printed Bengali Character, 10-11.

${ }^{18}$ Halhed, considered the design of Jackson's Bengali types to be a failure; Halhed, Grammar, xxiii.

${ }^{19}$ Halhed, Grammar, 17
} 
This approach, appropriate to the book's pedagogic purpose, is perhaps surprising since the notion of 'phalā' normally related to the use of 4 semivowels rather than the 11 phalās listed by Halhed; and many Bengali conjuncts obtain markedly different forms to their base consonants for which specific typeforms would need to be designed. [fig. 3] However, the use of 'subordinate and subsidiary figures' seems to have influenced Wilkins's typographical approach: the concept of having reduced forms of certain letterforms that could be attached to any consonant in order to form a conjunct was adopted, although not for all conjuncts, with varying degrees of success throughout the Grammar. Their obvious use is often revealed by gaps between elements and by ill-fitting or inconsistent combinations that occupy greater depth or appear larger than other characters [figs. 4 \& 5].

Halhed is known to have possessed models of good Bengali chirographic practice when composing the Grammar $;{ }^{20}$ Wilkins would likely have known which Bengali passages, and therefore conjuncts, would be rendered in print; and given the now known involvement of Joseph Shepherd, a gem-engraver, in cutting the types, it appears evident that that there was a deliberate attempt to simplify the script for foreign consumption, i.e. for East India Company servants to learn Bengali. The typeface was not intended for native readers. ${ }^{21}$ The use of shared components reduced the need to produce a sort for each consonantal cluster, thereby considerably reducing the size of the fount, and hence the cost of its production. Nonetheless, with regard to the 'set of Type of the Bengal language, and the printing of the Grammar ... the Governor General ... reported that much expense had been incurred in bringing this art to its present degree of perfection'. ${ }^{22}$ The complete fount used for the Grammar, and later publications of the Honourable Company's Press of which Wilkins was the Superintendent, comprised some 170 sorts. Its style, that owes much to Latin typographic sensibilities in its character formation and its typographic use, set a standard in terms of character shaping and method of composition that was emulated by other presses for some years to come.

It is interesting to note the great degree of variation in character-set sizes of Indian scripts prior to the mechanization of typefounding and typesetting. This is well exemplified at the initial stages of Indian-script type development by the activities of the Serampore Mission Press, established in 1800 by William Carey, Joshua Marshman, and William Ward, which by 1832 was reported to have published 'over two hundred and twelve thousand volumes in

\footnotetext{
${ }^{20}$ Halhed is known to have possessed a number of manuscripts: one, a copy of Kṛttivāsa's Rāmayāna bears Wilkins's initials, and two others are unusual for being in codex [portrait] format and including interword spacing, practices that Wilkins adopts for the Bengali texts [illustrated in Ross, Printed Bengali Character, 5, 6].

${ }^{21}$ As stated on the title page 'for the sake of the foreigner'; see fig. 5.

${ }^{22}$ IOR: Bengal Letters Received, Feb 1779 to Mar 1780, 39-40; letter dated 9 Feb 1779.
} 
forty languages', ${ }^{23}$

The adoption of Wilkins's method of Bengali composition by the Serampore Missionaries was probably inevitable since William Carey 'inveigled ... into his service' Pañcānana Karmarkāra to cast Bengali types..$^{24}$ Karmakāra, a blacksmith by trade, had also assisted Wilkins in the production of the types for Halhed's Grammar, and had continued to work for him at the Honourable Company's Press. The Bengali fount, cast in Calcutta for Carey, with the addition of some 'Pholās' cast at Serampore, was employed to compose the Bengali New Testament, Mañgala Samācāra, and also the first Bengali prose book, Rājā Pratāpāditya Caritra by Rāma Rāma Vasu, both published in 1801. Of interest is that Karmakāra, who remained with the Serampore Mission Press, did not employ a method of using common components to create the relatively more straightforward Devanagari conjuncts that the missionaries required initially for Sanskrit and Hindi. Karmarkāra's Devanagari fount was recorded as requiring 'seven hundred separate punches, of which onehalf had been completed' in $1803 ; 25$ a later Serampore Devanagari fount comprised 'nearly 1000 different combinations of characters' ${ }^{26}$

How does one account for this disparity in character set sizes (possibly well over 500 sorts) in founts used by the same press for related scripts representing the Indian phonological system? At the outset, as in all type development, judgements would have been made regarding what languages were to be represented by the typefaces, and therefore which characters needed to be included beyond the basic syllabary, vowel signs, modifiers, numerals, and punctuation. Indubitably, the classical Sanskrit language would have required a great many conjuncts that could occupy considerable depth. ${ }^{27}$ It is stated that translations of the New Testament 'prepared by Carey' also included Braj, Kanouji, Marwari, Bikaneri, and Maghadi 'which use different styles of Devanagari' $;{ }^{28}$ Nepalese is also listed. ${ }^{29}$ Some Marathi publications were set in Devanagari, but the Serampore Missionaries deemed it was not the most suitable script for composing Marathi, for which a fount of Modi types was created. ${ }^{30}$

\footnotetext{
${ }^{23}$ G.A Grierson, The Early Publications of the Serampore Missionaries: a Contribution to Bibliography', Indian Antiquary, XXXII (June, 1903), 241.

${ }^{24}$ B.S. Kesavan, ed., The Carey Exhibition of Printing and Fine Printing, The National Library, Calcutta, (Calcutta: The Government of India Press, 1955), 18.

${ }^{25}$ Marshman, Vol. 1, 179. A 'punch' is a piece of steel engraved with a type character and hardened, used for making matrices.

${ }^{26}$ Whereas an Oriya script fount comprised 'about 300 separate combinations'. Memoir Relative to the Translations of 1807, cited in George Smith, The Life of William Carey, Shoemaker and Missionary (London: John Murray, 1885), 243.

${ }^{27}$ Many being vertically stacked; Tibetan conjuncts can occupy an even greater depth through vertical stacking.

${ }^{28}$ Naik, Typography of Devanagari, Vol. 1, 280.

${ }^{29}$ Smith, Life of William Carey, 238.

${ }^{30}$ Smith, Life of William Carey, 243; illustrated in Naik, Vol. 1, 279.
} 
During what may be described as the infancy of South Asian typographic development, the Missionaries were also occupied with printing textbooks, grammars, and dictionaries in a range of languages for Serampore College and Fort William College where Carey taught. These publications served to help fund their proselytizing activities. Predictably, the sizes of the fount repertoires waxed and waned over the years, but improvements in script representation of Bengali ${ }^{31}$ and cost considerations regarding Devanagari saw the respective character sets grow somewhat closer in size and adopt more similar methods of composition. Whereas the design of the Serampore Missionaries' typefaces, whose development included founts to represent Sindhi, 'Pushtoo', and Singhalese, could be regarded as mediocre, and their earliest attempts at printing as less than proficient, fidelity to language and typographic experimentation were encouraged to answer 'the important question, how the greatest number of clear and legible copies can be furnished at the least expense'. ${ }^{32}$

Such experimentation was continued by John Lawson, yet another 'Serampore deserter' at the Baptist Mission Press in Calcutta, ${ }^{33}$ a dexterous punch-cutter who oversaw the production of typefaces inspired by local writing-masters and informed by scribal culture. Here we find the first steps in resolving the tension, that periodically recurs throughout South Asian type history, between professional type founders lacking a deep knowledge of the writing system and those who were fully conversant with the script and its requirements for authentic language representation, but who were unskilled in typographic practices. By 1821 a deepened understanding of the requirements of readable vernacular type is visible in Wilkins's fourth Bengali fount, which contained more integrated conjuncts and ligatures. ${ }^{34}$ The Baptist Mission Press's 1826 type-specimen book also demonstrates the expansion of Bengali founts to include some ligatures and the design of the majority of the conjuncts as one sort of approximately the same depth, infusing elegance and greater readability to the printed script. This publication includes the fount 'Bengalee No. VI' 35 that was employed for Lukalikhita Susamācāra [The Gospel by Luke] in 1831. Created by the London type founder Vincent Figgins, and after design improvements enjoying over one century of use, it exhibits highly professional typefounding practices developed for South Asian scripts during the nineteenth century. [fig. 6].

\footnotetext{
${ }^{31}$ Also used for their Assamese and Manipuri publications.

${ }^{32}$ A Memoir of the Translations for 1813, 20. Experiments were conducted to reduce the size of Devanagari conjuncts as the early founts proved expensive in terms of paper consumption. See Ross, Printed Bengali Character, chapter 3 for an evaluation of Bengali typefaces.

33 The schism is well documented, including by the younger missionaries: Eustace Carey and William Yates, Vindication of the Calcutta Baptist Missionaries (London, 1828).

${ }^{34}$ See F. Ross and G. Shaw, A Specimen of Bengali and Modi Types. (Andoversford, Whittington Press, 1987).

${ }^{35}$ Bengalee No. VI, later versions appear in British type-specimen books as 'Pica Bengalee' and 'Bengal on Pica Body'.
} 


\section{Establishing standards}

By 1826 Figgins, a former apprentice of Joseph Jackson, whose 'reputation as an excellent artist' was already established ${ }^{36}$ had considerable experience in the production of Indian-script founts. He had produced a polished Telugu typeface commissioned by the East India Company, as shown in extant type-specimen sheets. The Specimen of a Fount of Telugu Types (1802) displays how he utilized his typefounding skills to interpret what must have been good chirographic models for the letterforms. However, its gracefulness owes more to the Western split-nib steel pen than the traditional stylus employed for inscribing Telugu manuscripts. This fount saw scant use, possibly owing to its uneconomically large type size. Nevertheless, the Specimen, which contains tables of 'radical consonants', 'combining consonants', etc., reveals Figgins's methodical approach to the abstraction of the handwritten script for typographic reproduction. ${ }^{37}$ This approach to non-Latin typefounding that relies on total comprehension - and consequent typographic deconstruction - of the respective writing-system is further confirmed by the published fount synopses of his foundry's accomplished Bengali and Devanagari founts. These synopses, possibly issued posthumously by Vincent Figgins's son, reveal the systematic determination of each character repertoire in concert with what Figgins had identified as the appropriate methods for composing the complex joining scripts of north India.

In 1824 Henry Townsend, printer to Bishop's College Press (Sibpur), had expressed the realization with regard to Bengali - but equally pertinent to other South Asian scripts that unless a huge character set was cast, the number of sorts 'no matter how well calculated, can never be made to answer for every species of work' ${ }^{38}$ This remark remains prescient. The necessity to cater for unexpected combinations - either to extend a fount's character repertoire to represent more languages than originally intended, or to incorporate neologisms and transliterations - has been a long-held concern of type-makers. To some extent, the phalā method of composition answered the need to generate additional conjuncts but the systematic use of components, or what were to become known as 'degrees' or 'half-forms' for the Devanagari script, was not fully developed until 1836 when an Indian named Thomas Graham cut the punches for a Marathi fount in the Devanagari script at the American Mission Press (Bombay). ${ }^{39}$ Aside from reducing the size of the letters, Graham 'considerably reduced the number of double letters, by making half letters, or sections of letters. This was also done

\footnotetext{
${ }^{36}$ Reed, Letter Foundries, 336-7.

${ }^{37}$ Specimen of a Fount of Telugu Types Cast by Vincent Figgins (London, 1802).

${ }^{38}$ Society for the Propagation of the Gospel (London), Records: letter to A. Hamilton, 26 July 1824.

${ }^{39}$ The use of half-forms is already detectable in the Alphabetum Brammhanicum and in Wilkins's Sanskrit types. However, this is the first successful deliberate recorded use of this technique to reduce the character set.
} 
in the Guzarati [sic] founts.' ${ }^{40}$ The type historian B. S. Naik explains 'One letter was divided in three parts horizontally so that Ukars and Matras could be joined easily'. This system is known as 'The Bombay (or Degree) Type'. ${ }^{41} \mathrm{He}$ comments further:

It is an admitted fact that the three-step setting of the Devanagari script is a laborious task and a difficult job from the point of view of justification. The fillings on the top and at the foot called Degrees drop out, creating cavities in which the nearby types slip, disturbing the alignment. The normal fount for hand composing Devanagari, in this style, consists of about 400 type sorts. Attempts have been made by punch-cutters to do away with the three-step setting by casting the velanti, $m \bar{a} t r \bar{a}$ and $u k \bar{a} r$ signs on their body with overhangings [kerns]. ${ }^{42}$ This system is known as Akhand in which the fount is made of over 600 types. ${ }^{43}$ [Fig. 7]

The two systems of Degree and Akhand, or close variations thereof, were adopted by most type foundries for South Asian scripts and even continued to influence the mechanization of Indian vernacular typesetting; their legacy is still visible in digital fonts. ${ }^{44}$

The Figgins Sanskrit Devanagari fount synopsis reveals what was probably the largest Indian-script fount repertoire issued at the time, comprising some 800 sorts. In this synopsis all base consonants are repeated with at least one kerning variation in order to make use of the Akhand system for the implementation of vowels, that are also partially kerned, or other modifiers. Potentially awkward combinations with subscribed vowels are provided as ligatures. The repertoire includes a large array of conjuncts, many of which are specifically required for Sanskrit; however, all base consonants that have a final vertical stroke also possess a half-form variant (whereby the vertical stroke is removed) to combine horizontally with a following consonant or conjunct in order to create additional combinations. The semivowel Ya has what can be termed as two 'post forms' for use as the final member of a consonantal cluster. [Fig. 8]. The foundry's Devanagari fount first saw use in Francis Johnson's Hitopadesa (1847) published by Stephen Austin, the then East India Company

\footnotetext{
${ }^{40}$ A.K. Priolkar, The Printing Press in India (Bombay, 1958), 84.

${ }^{41}$ Being subscribed or super-scribed vowel signs respectively. The reduction in size radically reduced the costs of printing and made the books more portable. Naik,Typography of Devanagari, Vol. 1, 297.

42 The 'kern' is the part of movable type projecting beyond the body; it continues to be used for current technology where a character element may overhang part of an adjacent character.

43 Naik, Typography of Devanagari, Vol. 2, 341-2.

44 This essay adopts the convention of using the modern spelling of 'fonts' for digital type; glyphs may be considered the digital equivalent to sorts.
} 
Printer. ${ }^{45}$

The Figgins 'Pica Bengali' fount synopsis is not as extensive. It employs the same method as the Sanskrit Devanagari of utilizing kerned variants for ease of vocalization, and also contains some special ligatures of vocalized consonants. Rather than horizontal halfforms, it has a few phalās, including raphalā, that are subscribed, although letterforms with raphalā are designed as fully integrated conjuncts - a practice that continued in almost all subsequent foundry founts. The fount's earliest known use in England was in 1861 for Duncan Forbes's A Grammar of the Bengali Language, which has the author's note:

The mark rephaa $\square$ or top r, is very liable to break off in the working of the press; and the same remark applies to the slender top of the long $i \square$, which then becomes long $a \square$. The reader will, I trust, have the charity to hold the author blameless in such cases. ${ }^{46}$

Figgins's Bengali repertoire of some 370 sorts, however, differed from what was to become the standard repertoire of just over 500 sorts established by the renowned Sanskrit scholar and Bengali literary figure, İśvaracandra Vidyāsāgar, one of the founders of the Sanskrit Press. In the preface to his hugely popular Bengali primer, Varnaparichaya $1855,{ }^{47}$ Vidyāsāgar explains some of his decisions regarding appropriate Bengali typographic representation that remain current.

It is observable that whilst the Figgins foundry's Indian-script founts were skillfully executed and highly readable, in design terms they were less creative than their counterparts that emerged from the increasing number of indigenous foundries like those attached to the Sanskrit Press and the Nirnaya Sagar Press. ${ }^{48}$ The latter, was founded in 1869 by Javaji Dadaji and was supplied with type from his own eponymous foundry (founded in 1864) that produced highly acclaimed Devanagari and Gujarati founts in a range of sizes and styles that continued in use long after Dadaji's death in 1892. The Nirnaya Sagar Press employed the Degree system of composition, despite known problems of vowel-sign displacement when justifying lines; ${ }^{49}$ in 1963 the Devanagari founts sold by its foundry, principally for Marathi,

\footnotetext{
45 A note in the Vincent and James Figgins 1845 type-specimen book, states the foundry had the matrices of an 'English Sanskrita' cut in Calcutta under the superintendence of Professor Wilson.

A 'matrix' is a copper mould from which type is cast.

${ }^{46}$ Duncan Forbes, A Grammar of the Bengali Language (London, 1861), Errata page.

${ }^{47}$ By 1890, there had been '152 editions of Varnaparichaya' of '10 to 20 thousand copies'. Prasun Datta,

"Bengali Letterforms from Vidyāsāgar to To-day," Printers Voice, vol. XIX, 4 (August, 1982), 3.

${ }^{48}$ The growth of printing presses in India was assisted by new Press Act (1835) that repealed previous controls on the press.

49 'In this sense 'justification' is the even spacing of words to a given measure.
} 
Sanskrit, and Hindi, comprised 600 characters. ${ }^{50}$ Remarkably, during Dadaji's lifetime his foundry produced twenty Marathi founts and fifteen Gujarati founts alongside forty founts of English heading types. The associated costs of the materials to cast and store such relatively large Indian-script founts was frequently commented upon $;{ }^{51}$ such costs were clearly not conducive to the development of as rich a number of different type sizes and styles as can be found in synchronous Latin type development. However, these Indian-script types of mid nineteenth century and early twentieth century indigenous foundries created design standards that were to become highly influential in non-Latin typefaces designed for subsequent technologies.

\section{Models of good practice}

In many cases one can only speculate as to what models were used for the design of the typefaces during these early ventures which established what were to become conventional typographic practices for South Asian scripts. Handwritten samples were manifestly a key component, but much depended on the writing skill of the scribe of the original model, the skill of the punch-cutter in interpreting the model (even if a native speaker, not all typefounding assistants in whichever country, were literate), and the influential factors of knowledge of the script and the fount's intended purpose. Early engravings showing inaccurate examples of South Asian scripts indeed suggest that the early types might be questionable representatives of scribal practices, particularly with regard to character proportions, fitting, letterform construction, and stroke modulation.

Despite having sight of accomplished manuscript hands, Wilkins's first fount runs counter to the normal stroke sequence of Bengali pen letterforms in which the final vertical stroke of many letterforms would be an upward stroke; as in other cases where typeforms deviate from Indian penmanship, it is unknown whether this was a misinterpretation of the lettering models consulted. It is, however, known that the hand of Bengali writing-master Kalikumāra Rāya informed the elegant, vibrant type designs of the Baptist Mission Press, and that the high-contrast heading types of the Javaji Dadaji type foundry skillfully display the customary stroke modulation created by the Indian reed pen, whereby the strokes of bowls thicken when meeting a vertical..$^{52}$ [Fig. 9] Yet there is a lack of information regarding the introduction of similar high-contrast modulation to the types of south Indian scripts, such as

\footnotetext{
${ }^{50}$ Naik, Typography of Devanagari, Vo. 1, x.

${ }^{51}$ Norman Ellis remarks in 1955 that up to 7 cases of book type (of one size only) are needed for bookwork for an Indian script. '.. the cost of maintaining a composing room for bookwork can be immense'. 'Indian Typography' in Kesavan, The Carey Exhibition, 11.

${ }^{52}$ In contrast to the pen used for Tibetan and for the Latin script.
} 
Kannada, that again contradicts the indigenous manuscript culture. As indicated above, manuscripts in southern India were incised on palm leaf by means of a stylus and then inked, producing mono-linear letterforms. The highly modulated forms shown in the crisp and very readable Kannada types of the Basel Mission Press (Mangalore) may stem from types brought to Mangalore by a printer from Basel in 1851, of which, regrettably, there is no available type specimen. ${ }^{53}$ Furthermore, the influence of the European split-nib pen, seen in Figgins's Telugu fount, recurs in the exceptionally graceful Tamil types of as yet unattributed authorship produced by the Nelson and Swadezi type foundries of Madras in the early twentieth century [fig. 10].

The continued influences of the early established types may result from the convention of type designs being closely followed, and even copied, rather than original design styles being initiated, largely owing to what has been perceived as reader conservatism. ${ }^{54}$ This is perhaps responsible for the custom of using low-contrast Gurmukhi founts for Punjabi texts, a custom that has persisted into the twenty-first century.

Just as it is hard to determine the models for the type designs, their precise authorship is often unclear. ${ }^{55} \mathrm{It}$ is regrettable that it has been a long-standing practice for many type foundries not to reveal the authorship of the typefaces, or for known authors not to acknowledge collaborators. Historical accounts, however, do provide details regarding local assistance in language learning and in translating. The remarkable achievements of the Serampore Mission Press, albeit to further its proselytizing activities rather than for benefiting indigenous communities with the faithful representation of local languages, would not have been realizable without the input of the munshis and pundits, or without local labour employed in the type foundries; although Carey, Marshman, and Ward were accorded most of the credit. ${ }^{56}$ Nonetheless, Manohara Karmarkāra, Pañcānana's eventual son-in-law, is acknowledged for his forty years work at the Serampore Mission Press: 'to whose exertions and instructions Bengal is indebted for the various beautiful founts of the Bengalee, Nagree, Persian, Arabic and other characters which have been gradually introduced into the different printing establishments'. ${ }^{57}$

The Arabic script was also used in South Asia for Pashtu and Sindhi. Although it

\footnotetext{
${ }^{53}$ The types may have been brought later in 1852; Graham Shaw, 'Printing at Mangalore and Tellicherry by the Basel Mission," Libri (27) 1. Lithography was used prior to and alongside these.

${ }^{54}$ See Ross, Printed Bengali Character, 193-4.

55 The more recent designation of type-designer is inappropriate here.

${ }^{56}$ Carey and Yates, Vindication, 39-40.

${ }^{57}$ J.C. Marshman, The Life and Times of Carey, Marshman and Ward, Vol. 1, London, 1859, 179. However, it cannot be determined which design decisions were undertaken by whom in cutting the types.
} 
enjoyed a longer period of typographic development than Brahmi-derived scripts, the calligraphic hand was preferred, especially for the representation of the Perso-Arabic script of Nasta'liq. The introduction of lithography, taken up in India from 1825, far surpassed what was achievable with metal type and became the standard means of representing Nasta'liq, particularly for the Urdu language, until the end of the twentieth century.

Whilst it is hard to assess the specific roles that were undertaken by even the acknowledged individuals in the design process of the early Indian founts - as hitherto printing histories have accorded scant attention to this subject and to the evaluation of the types $^{58}$ - it is noticeable that throughout South Asian type history examples of good practice resulted from collaborative typographic endeavours. Moreover, with the advent of mechanization, collaboration became critical to the development of founts for the textual representation of Indian languages.

\section{Overturning conventions}

Unlike previous typographic developments for hand-composition, the impetus to implement Indian scripts for hot-metal mechanical composition can be seen as neither evangelical nor colonial but primarily commercial:

it must be emphasised that the Linotype is as essential as the Typewriter for a progressive nation. Its necessity is already being felt by Printers in General and Newspaper Offices in particular. ${ }^{59}$

The Linotype line-casting machine, that was ideally suited to the pressures of efficient newspaper production by rotary printing, created problems even for non-joining scripts like Kannada on account of the severely restricted character-set demanded by the 90-channel keyboard. Numerous proposals emerged from different quarters, including from the Linotype Company itself, ${ }^{60}$ regarding how to resolve the issues of regional language representation with a limited number of sorts. Script reforms were proposed for various Indian languages by different committees that had some influence on Linotype's fount-making decisions, although such proposals even if supported by government departments were not officially

\footnotetext{
${ }^{58}$ B.S. Naik's work on Devanagari typography has been the exception, although the assessment of the designs is rudimentary.

${ }^{59}$ K. Sree Vijayapaliah, Introduction of Kannada on the Typewriter, Linotype and Monotype, (Bangalore, 1954), 2. Arabic hot-metal typesetting pre-dates that for Indian scripts; see Titus Nemeth, "Arabic Hot Metal: The Mechanisation of Arabic typography" in this Journal.

${ }^{60}$ Mergenthaler Linotype Company in the US and Linotype \& Machinery Ltd in England.
} 
binding on the company's commercial ventures into South Asia.$^{61}$ For Linotype the requirement for fast typesetting speeds to meet the demand for newspaper production on a par with 'the big English dailies' ${ }^{62}$ ultimately resulted in the renewed systematic deconstruction of each Indian script under consideration.

Characters were again to be split into components, but with the Linotype machine there was no possibility of kerns or 'overhangs': neither the Akhand nor the Degree composing systems were feasible. Information on script behaviour and design preferences was afforded to Linotype by different parties: Linotype agents, well-informed clients, and academic consultants, but their exertions documented in company archives were compromised by the limitations dictated by the exigencies of the machine. Some languages were more affected than others.

For Kannada composition type foundries had already reduced the number of combinations by utilizing separate elements to link horizontally connecting vowel signs, but this still left 249 characters for normal composition, of which 63 infrequent used characters could be allocated to a side-case. ${ }^{63}$ The proposal to reduce the set further by splitting the specific vowel-sign terminations above consonants - a practice used for large-sized foundry type until its elimination at the beginning of the twentieth century due to its 'ugly looking deformations' - was deemed only acceptable for newspaper composition. However, the concomitant $25 \%$ decrease in keying speeds occasioned by the need for two keystrokes to compose these frequent characters was unfavourable to newspaper production. ${ }^{64}$

The Linotype's inability to kern - which also necessitated the positioning of subscripts separate from their host consonants - and the use of half-forms to create all conjuncts, lent Devanagari texts an unusual 'broken' texture [fig. 11]. ${ }^{65}$ But this was not as profound as in the case of Bengali. Years of collaboration between the distantly situated Linotype companies in England and America and the leading Calcutta newspaper publisher Ananda Bazar Patrika,${ }^{66}$ whilst enabling the effective dissemination of information, introduced a radically different visualization of the Bengali language that became its customary textural guise for 40

\footnotetext{
${ }^{61}$ See V. Singh's insightful essay on the issues regarding Devanagari "The machine in the agency of change: Devanagari Linotype and the script reform movement".

${ }^{62}$ Vijayapaliah, Introduction of Kannada, 2.

${ }^{63}$ In practice, handpicking type from a side-case was avoided as it incurred additional expense and further reduced composing speeds. See Nemeth, "Arabic Hot Metal", 7.

${ }^{64}$ According to a Linotype document this method would incur ' $15 \%-40 \%$ increase in thin matrices, with the attendant troubles such as frequently getting bent ...', 2. (Non-Latin Type Collection, University of Reading). ${ }^{65}$ Which had also affected Arabic composition; Nemeth, "Arabic Hot Metal", 7.

${ }^{66}$ Correspondence averaging one month's delivery between countries in the 1930s; Ross, Printed Bengali Character, 141.
} 
years [fig. 12]. Furthermore, duplexing, whereby the Light and the Bold characters with a few exceptions occupied the same matrix - and therefore the same widths - seemingly accounts for the manner in which weight is still currently applied with scant horizontal expansion to all South Asian scripts [fig. 13]. More remarkably, the introduction of standalone vowel signs to the Malayalam script introduced by Linotype remains common practice, for no technological reason, and is even found in contemporary hand lettering.

It should be recalled that the different typefounding and typesetting technologies by no means operated sequentially in South Asia but often ran in parallel: hand-composition continued alongside mechanized typesetting, and although foundries were perhaps more affected by the introduction of the Monotype composing machine in the 1920s, to some extent they benefited from it. ${ }^{67}$ In 1984 India was recorded as having more Monotype hotmetal machines, comprising a keyboard and a caster, than any other country; ${ }^{68}$ its Super Caster machine was frequently used to cast type into case to supplement hand-setting despite the metal being weaker than foundry type.

The Monotype was able to utilize a form of the Akhand system, and although insufficient for many South Asian scripts, it had a much larger character set than the Linotype at its disposal, namely 225 (later 255) sorts. However, its introduction of the relative-unit system, which the Linotype later adopted, for its justification mechanism dictated specific width allocations that compromised letterform proportions. Unexpectedly, the Gujarati script was greatly affected by the consequences of mechanization by Monotype. This non-joining script, possessing a smaller character set than Devanagari, suffered in its implementation through ill-fitting half-forms; overlarge subscripts (to reduce type breakage) that necessitated the cropping of significant finials and the 'near decapitation' of some frequent consonants; the truncation of exit strokes in the Bold fount; and noticeable inconsistent design issues. Monotype prided itself on its founts being favourably compared with founders' types, but the result was a far cry from the elegant Gujarati forms displayed in newspapers like Janmabhoomi in 1947. Again the consequences remain evident today, since with the advent of photocomposition Monotype followed the most economical convention of conversion rather than innovation by transferring existing designs to the new technologies of filmsetting and digital typesetting [fig. 14]. For example, Tamil composition, whose wide characters had to be made small on the body in mechanical typesetting, was characterized for more than half a century by the combination of a small appearing height and subsequently over-wide Latin

\footnotetext{
${ }^{67}$ In 1982, it was estimated that more than 300 type foundries were operating in the Indian sub-continent. Paritosh Dhar [Address to] $7^{\text {th }}$ Conference of All Indian Typefounders, (Calcutta, 1982), 6 .

${ }^{68}$ John Randle, 'The Development of the Monotype Machine," Matrix 4, (Andoversford, Winter, 1984), 47.
} 
word-spaces ${ }^{69}$ that produced 'rivers' of space in narrow newspaper columns, an effect which is still noticeable in current publications.

Many Indian scripts transferred from metal type directly to digital technology and circumvented filmsetting, yet the experience gained by attempts to implement non-Latin scripts on filmsetters profoundly affected digital composition of South Asian languages. The ability to overlap elements in film was especially favourable to joining scripts (although this was not often utilized to best effect, particularly with the conversion of existing designs). ${ }^{70}$ Furthermore, the incorporation of computer software into filmsetters such as Linotype's V-I$\mathrm{P}$ provided a mode of positioning accents (superscripts) that was to become more refined in digital composition. However, it was the software specifically introduced for V-I-P Arabic to select contextual forms that lead to fundamental and far-reaching innovations for the composition and visual representation of Indian languages.

\section{Exploiting possibilities for improved language representation}

Inspired by the introduction of Arabic character-selection logic for the V-I-P phototypesetter, for which some Indian scripts had been developed but which still required one character per key-code, ${ }^{71}$ the Phonetic Keyboard for digital composition was invented at Linotype in 1978. ${ }^{72}$ This keyboard, on which only the basic syllabary was required alongside modifiers, punctuation, and numerals, allowed conjuncts or ligatures to be created by a special conjunct key, and effectively liberated the typeface design artwork from dedicated and expensive hardware.

The facilities first afforded by the Linotron 202 digital typesetter driven by the Phonetic Keyboard were numerous: being able to handle character-sets greater than 256 characters (then by merging fonts); to kern in both directions by small increments; to manage wide letterforms (then by adding units to extra-wide glyphs); to precisely position superscripts and subscripts whilst providing vertical offsets for specific sequences; to cater for regional preferences; and, above all, to access contextual forms. All these are now familiar features available to the designer of present OpenType format fonts. ${ }^{73}$ Yet these facilities were

\footnotetext{
${ }^{69}$ Numerals were often borrowed from the Latin, partly to reduce the character set, which were also oversized.

${ }^{70}$ And benefitted characters created by joining elements - although, surprisingly, gaps continued to be visible between elements creating Devanagari conjuncts even into digital technology and in new designs.

${ }^{71}$ An unsigned Linotype in-house document regarding Kannada script for the V-I-P (which was never realized) states 'without a character selection program 6 fonts would be needed and there would be up to 6 characters (in each weight) to a single key. Operation would be tedious.' 1/8/74. (Non-Latin Type Collection)

72 By Dr. Mike Fellows and the author; see Ross, Printed Bengali Character, 216-220.

${ }^{73}$ For which character widths are no longer an issue, but overall dimensions may be affected by deep vertically stacked conjuncts. See F. Ross, 'Non-Latin scripts: key issues in type design' in eds Ross and Singh, Non-Latin scripts, 139, 141.
} 
developed and made available specifically for improved representation of South Asian scripts in the early 1980s by Linotype's development work in Cheltenham (UK) and with information from Linotype agents and clients in India, and from typographically aware academics at the School of Oriental and African Studies (London University). However, then and during the era of PostScript that initiated desktop publishing, these features were only available by means of proprietary software. At that time technological innovation at Linotype was exploited for design innovation: new typeface designs of enduring quality emerged that introduced new standards for regional language communication. Unfortunately, these failed to act as a spur to continued innovation; rather, the designs were frequently copied and forty years on their clones appear in formats that betray the legacy of even earlier practices.

Typographic composition in South Asian languages remains compromised by the continuing paucity of high-quality fonts for visual communication. Today, when affordable and accessible font-making tools are able to handle complex scripts, and yet when non-Latin scripts lag behind Latin in terms of the choice and even readability of available fonts, it is timely to question type-design decisions in vernacular communication. Comprehending the impacts of past technological practices that were crucial in determining the textual and textural appearance of South Asian languages can enable the interrogation of the effectiveness of present typographic practices. Scrutinizing relevant archives, consulting authoritative sources, and referencing synchronous chirographic material can contribute to informed decision-making in the creation of original designs for the optimal visual representation of the polyphony of voices of South Asia.

[Figure 15] 


\section{Bibliography}

Carey, Eustace and Yates, William. Vindication of the Calcutta Baptist Missionaries. London:

Wightman \& Co., 1828.

Carey, William. A Grammar of the Sungskrit Language. Serampore, 1804.

Coulmas, Florian, The Writing Systems of the World. Oxford: Basil Blackwell Ltd, 1991.

Datta, Prasun. "Bengali Letterforms from Vidyasagar to To-day." Printers Voice, XIX, 4 (August, 1982): 1-9.

Dhar, Paritosh [Address to] 7th Conference of All Indian Typefounders. Calcutta, 1982.

Ellis, Norman. "Indian Typography." In The Carey Exhibition of Printing and Fine Printing. The National Library, Calcutta, edited by B.S. Kesavan. Calcutta: The Government of India Press, 1955.

Grierson, G.A. "The Early Publications of the Serampore Missionaries: a Contribution to Bibliography."Indian Antiquary, XXXII (June, 1903), 241-254.

Figgins, V., Specimen of a Fount of Telugu Types Cast by Vincent Figgins. London, 1802.

Figgins, V. \& J., New Specimens; Oriental Types. [London, 1884]

Forbes, Duncan. A Grammar of the Bengali Language. London: Wm. H. Allen, 1861.

Halhed, N.B. A Grammar of the Bengal Language. Hoogly, 1778.

Kesavan, B.S., ed. The Carey Exhibition of Printing and Fine Printing. The National Library,

Calcutta. Calcutta: The Government of India Press, 1955.

Linotype \& Machinery Ltd, A Dictionary of Printing Terms, London, 1962.

Marshman, John Clark, The Life and Times of Carey, Marshman and Ward, 2 vols London, 1859.

Marshman, Joshua. A Memoir of the Translations for 1813, Kettering: Baptist Missionary Society, 1815.

Naik, B.S. Typography of Devanagari. 3 vols, Bombay: Directorate of Languages, 1971.

Pollock, Sheldon. "Literary Culture and Manuscript Culture in Precolonial India". In Literary

Cultures and the Material Book, edited by Simon Elliot, Andrew Nash \& Ian Willison, London: The British Library, 2007, 77-94.

Priolkar, A.K. The Printing Press in India, Bombay: Marathi Samshodhana Mandala, 1958.

Randle, John. "The Development of the Monotype Machine." Matrix 4, Andoversford:

Whittington Press (Winter, 1984): 42-49.

Reed, Talbot Baines. A History of Old English Letter Foundries. London: E. Stock, 1887.

Ross, Fiona. The Printed Bengali Character and its Evolution. Richmond: Curzon Press, 1999.

Ross, Fiona. "Non-Latin scripts: key issues in type design." In Non-Latin scripts: From hot-metal to digital type, edited by Fiona Ross and Vaibhav Singh, 125-153. London: St Bride Library, 2012. 139, 141.

Ross, Fiona and Shaw, Graham. A Specimen of Bengali and Modi Types. Andoversford: Whittington Press, 1987.

Shackle, C. and Skjaervo, P.O. "South and SouthEast Asia: Scripts." In Encyclopedia of 
Languages and Linguistics, edited by K. Brown, $2^{\text {nd }}$ edn, 11: 544-57. Oxford: Elsevier, 2006.

Shaw, Graham. "Non-Latin scripts and printing technologies". In Non-Latin scripts: From hotmetal to digital type, edited by Fiona Ross and Vaibhav Singh, 11-33. London: St Bride Library, 2012.

Shaw, Graham. "Printing at Mangalore and Tellicherry by the Basel Mission". Libri (27) 1, (1977): 154-164.

Shaw, Graham. "Printing in Devanagari - Monotype's important role in the growth of printing in India." The Monotype Recorder, New Series, 2, (September, 1980): 2-33.

[Shaw, G.] "Indian Manuscripts, An introduction to the permanent exhibition," British Library information sheet, 1977

Smith, George.The Life of William Carey, Shoemaker and Missionary. London: John Murray, 1885.

Vidyāsāgar, İśvaracandra,Varnaparichaya, Calcutta: The Sanskrit Press, 1855

Vijayapaliah, K. Sree, Introduction of Kannada on the Typewriter, Linotype and Monotype, Bangalore: Government Press, 1954.

Archival Collections:

British Library: IOR: Bengal Letters Received, Feb 1779 to Mar 1780, pp. 39-40; letter dated 9 Feb 1779.

Kannada folder: Non-Latin Type Collection, Department of Typographic Communication, University of Reading. 